\title{
Concepções de normalidade e saúde mental entre infratores presos de uma unidade prisional da cidade do Salvador
}

\author{
Conceptions of normality and mental health among prisoners \\ in a correctional institution in the city of Salvador
}

M aria Thereza Ávila Dantas Coelho ${ }^{1}$

${ }^{1}$ Universidade do Salvador. Alameda das Espatódias

$\mathrm{s} / \mathrm{n}$, Caminho das Árvores. 41820- 460

Salvador BA.

therezacoelho@pop.com.br

Abstract Although in Brazil some recent studies analyzed the concepts of normality and mental health, therearestill no investigations dealing with thisquestion among prisoners. Thus, this work aims specifically at investigating this subject in this segment of the population. The methodology used in this study was collection of data and practical analysis according to the theory of systems of signs, meanings and practices. We verified that the interviewees associated normality and mental health with the behaviors considered normal and sane in the scientific literature. The inverse occurred in relation to the concepts of abnormality and insanity. A relevant aspect of this study was the prisoner's approach to criminal violence. At the same time they considered such type of violence as characteristic of an abnormality or illness, they did not consider themselves abnormal or violent for having committed a crime. This aspect seems to point to the existence of two different perspectives: one considering criminal violence as abnormal or insane and another that admits the coexistence of a moment of criminal violence with normality and mental health.

Key words Health, Normality, Criminal violence, Prison
Resumo Apesar de recentemente no Brasil alguns estudos terem se dedi cado à investigação dos conceitos de normalidade e saúde mental, inexistem ainda pesquisas que tratem desta questão entre infratores presos. Este trabalho pretendeu, justamente, investigar tal tema nessa parcela da população. Para tanto, utilizou o referencial metodológico de coleta eanálisededados da teoria dos sistemas de signos, significados e práticas. Verificamos que, na perspectiva dos entrevistados, a normalidadeea saúde mental estão associadas aos comportamentos apontados pela literatura científica como normais e saudáveis, o inverso ocorrendo em relação aos conceitos de anormalidade edoença mental. Um aspecto relevantedesteestudo é a forma pela qual a violência criminal foi abordada pelos detentos. Ao mesmo tempo em queeles conside raram tal tipo de violência como característico de uma anormalidade ou doença, não se consideraram nem anormais nem violentos por terem cometido um delito. Esse aspecto parece apontar para a existência de duas diferentes visões: uma que reproduz 0 primeiro tipo deassociação, e outra que admitea coexistência deum momento deviolência criminal com o estado de normalidade e saúde mental.

Palavras-chave Saúde, N ormalidade, Violência criminal, Penitenciária 


\section{Introdução}

Cada vez mais a cidade de Salvador tem sido alvo da violência urbana. A pesar desse crescente fenômeno, é grande a carência de estudos que revelem como os infratores concebem a normalidade e a saúde mental. 0 conhecimento desse aspecto é essencial para o planejamento de ações de saúde nas comunidades. As novas políticas públicas têm apontado, justamente, para a importância de ações intersetoriais. N essa direção, a saúde vem sendo pensada como algo a ser construído não apenas pelo setor saúde, mas também por outros setores da sociedade. Apesar da crescente discussão sobre esse ponto de vista, poucos estudos têm sido feitos no sistema penitenciário. As pesquisas têm excluído essa parcela da população, mantendo-a à margem da sociedade no que diz respeito às suas concepções e práticas de vida.

0 objetivo principal deste estudo foi, então, investigar os signos, significados e práticas relacionados à normalidade e à saúde mental por infratores presos. De acordo com a teoria dos sistemas de signos, significados e práticas ${ }^{1,2}$, os signos se referem aos comportamentos que apontam para a normalidade, saúde e doença mental. Os significados dizem respeito às idéias apresentadas sobre esses temas. As práticas compreendem as reações das pessoas aos indivíduos considerados normais ou anormais, sejam elas de restauração ou manutenção da normalidade.

\section{Os conceitos de normalidade e saúde mental}

Os conceitos de normalidade e saúde vêm sendo

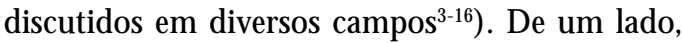
tem-se reafirmado o desinteresse da parte de todas as disciplinas que compõem o campo da saúde na construção do objeto "saúde" 8 . De outro, tem-se apontado que o conceito de saúde tem tomado feições particulares, a depender do contexto teórico e prático do campo que o adote como uma questão importante e inerente ao seu próprio universo ${ }^{16}$.

Em linhas gerais, a investigação desse conceito tem girado em torno dos três eixos definidos pela Organização Mundial da Saúde (OMS) como pertencentes à sua estrutura: os eixos biológico, psicológico esocial. No eixo biológico, édigno denota o desenvolvimento teórico realizado por CanguiIhem ${ }^{17}$, referência epistemológica fundamental para o próprio desenvolvimento do campo da Saúde Coletiva. Esse autor criou uma distinção original entre a normalidade e a saúde, ao tempo em que efetuou um rompimento com a visão tradicional destes conceitos enquanto adaptativos às normas científicas e sociais vigentes. Outra referência importante do eixo biológico, recentemente tratada por Almeida Filho e Jucáa ${ }^{10}$ é o pensamento de Christopher Boorse que, numa direção contrária à de $C$ anguilhem, mantém-se na perspectiva tradicional da compreensão da saúde enquanto ausência de doença e vice-versa.

No eixo psicológico, por sua vez, a referência primeiraé, inegavelmente, a obra deSigmund Freud que, jáno início do século XX, rompeu com adisjunção entre os fenômenos normais e patológicos, defendendo que ambos são produtos de mesmos mecanismos mentai $s^{18-23}$. Essa compreensão não o impediu de tecer alguns critérios diferenciais entre tais fenômenos, importantes para a condução do tratamento dos pacientes que se submetem a um processo de análise ${ }^{24}$. No campo da psicopatologia, por seu turno, Jaspers ${ }^{25}$ é certamente um dos autores de referência, por ter distinguido, dentre outras coisas, o conceito de normalidade do de normalidade estatística. Na psicologia, especificamente, a prática profissional que tem se desenvolvido nas unidades de saúde tem fomentando a discussão sobre tal conceito, inclusive em outras áreas de atuação do psicólogo, conforme aponta 0 estudo recente de M edeiros et al. ${ }^{16}$.

No eixo social, por fim, merecem destaque os trabalhos dos teóricos do rótulo, dos antropólogos médicos ou da saúde, dos etnopsiquiatras e etnopsicanalistas. Dentre os teóricos do rótulo, Goffman ${ }^{26}$, Becker ${ }^{27}$ e Scheff ${ }^{28}$ são autores de referência, que problematizaram os efeitos do estigma no tratamento social das pessoas consideradas como doentes mentais, apontando para a importância dos papéis sociais a partir da classificação dos indivíduos. No campo da antropologia médi$\mathrm{ca}$, por sua vez, autores como Kleinman ${ }^{29-31}$, Good $^{32,33}$, Young ${ }^{34}$, Bibeau ${ }^{35}$ e Corin ${ }^{36}$, dentre outros, têm chamado a atenção para a relevância dos significados atribuídos pelos indivíduos aos seus processos de saúde-doença, no que diz respeito às buscas e alianças terapêuticas efetuadas nas diversas esferas do cuidado à saúde. $\mathrm{N}$ a etnopsiquiatria clássica, por seu turno, Devereux ${ }^{37}$ buscou chamar a atenção para a interação dos fenômenos patológicos com aspectos culturais, propondo, a partir daí, uma definição para o próprio conceito de saúde. $\mathrm{Na}$ etnopsicanálise, por fim, Laplantine ${ }^{38}$ propôs critérios epistemológicos para o conceito de normalidade.

A partir desses três eixos estruturantes, o biológico, o psicológico e o social, Samaja ${ }^{39}$ lançou 0 projeto de construção de uma teoria geral da saúde, buscando integrar os aspectos biopsicossociais 
em diferentes níveis hierárquicos componentes do objeto "saúde". Tal proposição tem encontrado eco fecundo no campo da Saúde Coletiva, cujos estudos têm buscado colaborar com a construção dessa teoria ${ }^{3-9,40-45}$. Inúmeras pesquisas têm sido, então, realizadas nesse campo, focalizando os conceitos de normalidadee de saúde, buscando o descentramento dos conceitos de enfermidadeou doença.

\section{Metodologia}

Esteestudo teve como referência metodológica a teoria dos sistemas de signos, significados e práticas $^{1,2,46,47}$. Essa teoria propõe que sejam estudadas não apenas pessoas do centro da sociedade, mas também as que se encontram à sua margem. Tal aspecto constituiu um dos fatores que motivou a realização desta pesquisa numa unidade prisional. A idéia foi, então, poder estender a essa parcela da população uma investigação quejá havia sido efetuada entre pessoas comuns, numa comunidade do litoral norte da Bahia ${ }^{7}$. A teoria dos sistemas de signos, significados e práticas considera extremamente relevante a apreensão de múltiplos pontos de vista para a compreensão de um dado problema. Tanto as concepções e experiências comuns quanto as singulares a cada sujeito possibilitam uma visão mais enriquecida e complexa do objeto de estudo.

Considerando essa orientação metodológica, após consentimento prévio, vinte e oito infratores presos, do sexo masculino, foram entrevistados a partir de um roteiro semi-estruturado. A grande maioria dos entrevistados se encontrava na faixa etária entre 20 e 30 anos de idade $(n=23)$, possuía o primeiro grau incompleto $(n=24)$, era solteira $(n=27)$, praticara o delito deroubo $(n=20)$ enunca havia feito qualquer tratamento psicológico ou psiquiátrico ( $n=25)$. Doze deles eram usuários dedroga. M etade dos crimes ocorreu na cidade de Salvador ea outra metadeno interior do estado da Bahia, conforme o local de residência dos mesmos.

Os dados coletados foram, então, agrupados de acordo com os objetivos do estudo, nas seguintes categorias: concepções de normalidade e saúde mental; concepções de anormalidade e doença mental; ações de promoção da saúde; ações de normalização ou cura; auto-percepção em relação à normalidade e saúde mental. Conforme a teoria dos sistemas de signos, significados e práticas, a análise dos dados se deu em dois níveis. No primeiro nível, buscou-se apreender as concepções de normalidade e saúde mental tais como elas foram explicitadas pelos entrevistados. No segundo nível, questões foram respondidas de acordo com as relações estabelecidas pela pesquisadora entre as concepções dos presos e o quadro científico da pesquisa. Com fundamento na semiótica contemporânea, buscou-se realizar uma leitura polissê mica e intertextual das narrativas, considerando a multiplicidade de sentidos, identificada através da interpretação ${ }^{46}$.

\section{Resultados ediscussão}

No que diz respeito às concepções de normalidade e saúde mental, os presos associaram a normalidade e a saúde a estudar, namorar, trabal har, ler a Bíblia, fazer esporte, ter boa família, saber efazer o que é certo, ter uma fisionomia normal, ser tranqüilo, paciente, tratar bem as pessoas, comunicarsecom elas, pensar positivo, ter consciência do que faz, pensar antes de agir, ser inteligente, confiante, cuidar da saúde, ser sadio, sentir-se bem, não agredir, não usar droga, não ser influenciável, não ter problema financeiro, não sentir ódio nem mágoa, não ter distúrbio mental, não pensar ou fazer 0 mal, não pensar ou cometer violência, não praticar o crime. Essas concepções podem ser visualizadas na Figura 1.

Tais resultados se mostram próximos do pensamento de autores como Freud, Goffman, Becker, Kleinman, Good, Bibeau, Corin, Boorse e Samaja, como vimos acima. Na perspectiva da psicanálise, a normalidade e a saúde estão ligadas à possibilidade de realizar atividades da vida cotidiana, com certo grau de autonomia e de eficiên$\mathrm{cia}^{18}$. Já na perspectiva dos teóricos do rótulo, elas implicam a adoção dos comportamentos esperados e desejados pel os membros de uma dada sociedade $^{26,27}$. No pensamento de Boorse, por sua vez, a saúde éapresentada enquanto ausência de doença ${ }^{10}$, perspectiva também encontrada entre os detentos. Na medida em que todas essas concepções envolvem aspectos biopsicossociais, elas se mostram concordantes com a proposição samajiana de distintos planos para o objeto "saúde" 39 . Todos esses significados produzem efeitos, portanto, no relacionamento cotidiano entreas pessoas, seja nos processos educativos e laborais, seja nas buscas terapêuticas entre aqueles que não apresentam os signos de normalidade e saúde mental ${ }^{29-33,48}$.

É interessante observar que esses resultados também se encontram próximos dos encontrados no já citado estudo realizado no litoral norte da Bahia ${ }^{7}$. N aquele estudo, entretanto, não foi explicitada a associação entre a normalidade, a saúde mental ea ausência de criminalidade. A penas a relação entre a normalidade, a saúde mental ea não- 


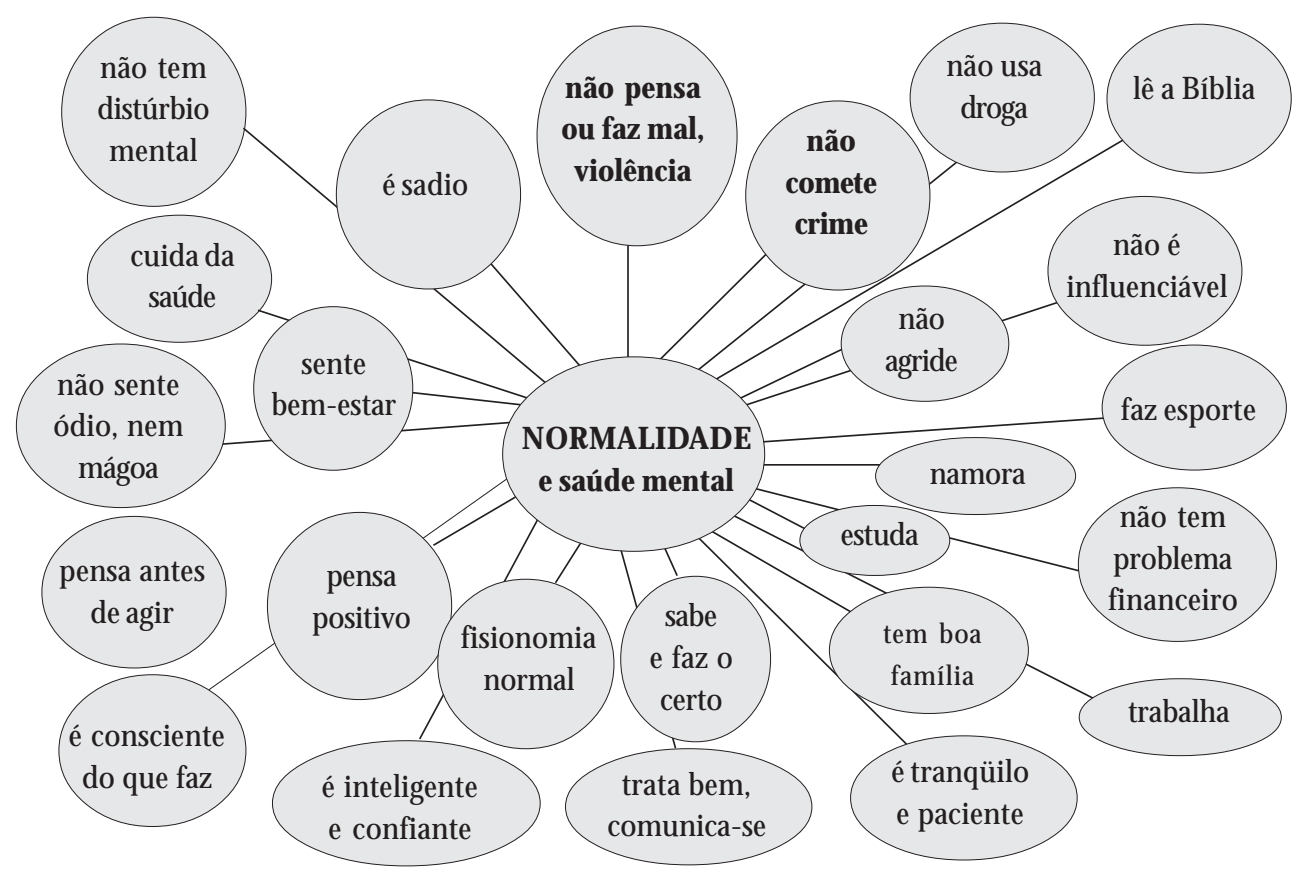

Figura 1. Concepções de normalidade e saúde mental.

ocorrência de comportamento agressivo foi apre sentada pelos moradores daquela região. Tal aspecto pode se dever ao fato de as pessoas não diretamente vinculadas ao universo do crime buscarem banir de seus pensamentos a violência criminal. $\mathrm{Na}$ população investigada por este estudo, entretanto, esse tipo de violência faz parte do cotidiano das pessoas, o que pode facilitar a emergência de tal associação. N esse universo, portanto, há uma relação de exclusão entre a normalidade, a saúde mental e 0 ato criminoso, de modo que, na visão dos entrevistados, a violência criminal não parece integrar a normalidade e a saúde mental.

Tal ponto de vista pode estar relacionado ao que os teóricos do rótulo definiram como estigma. De acordo com esses teóricos, como vimos, a sociedade estabelece os meios de classificar as pessoas em categorias, de acordo com os seus atributos $^{26}$. Os que apresentam os atributos socialmente desejados são categorizados como normais, enquanto que aqueles que possuem um ou mais atributos indesejáveis são considerados desviantes. Os signos marcadores do desvio constituem os estigmas a partir dos quais são identificados os desviantes. Como a condenação judicial e o tratamento social recebido pelos presos fazem com que eles sintam efetivamente que o crimeé indesejado pela sociedade, eles apreendem a relação de exclusão quea violência criminal mantém com as noções de normalidade e saúde.

Passemos agora às concepções de anormalidade e doença mental. Os detentos relacionaram a anormalidade e a doença aos comportamentos de não estudar, não respeitar o outro, não se comunicar, não pensar antes de agir, não ter consciência do que faz, à ausência de bem- estar e saúde, à presença de distúrbio mental, estresse, depressão e angústia, à oscilação do bem-estar, problema de "nascença", nervosismo, agitação, mudança na fisionomia, presença do demônio, dificuldadefinanceira, descontrole, comportamento inadequado, fazer coisa errada, maldade, uso de droga, agressão, violência e crime. Tais resultados podem ser visualizados na Figura 2. 


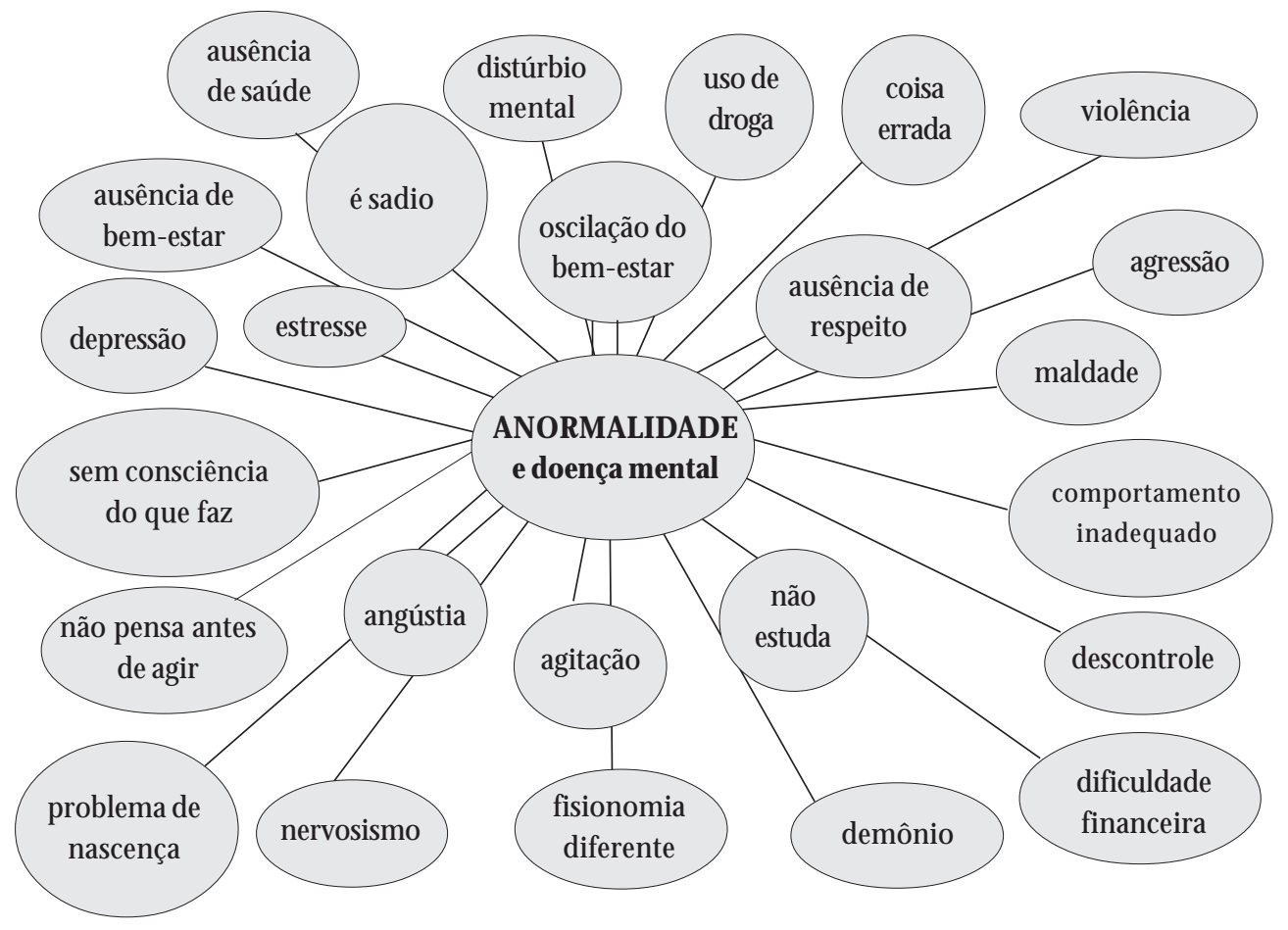

Figura 2. Concepções de anormalidade e doença mental.

É interessante observar que esses resultados apontam para uma concepção de oposição entre a normalidade e a saúde mental e a anormalidade e a doença mental, de modo que estas duas últimas parecem ser o contrário das duas primeiras. A título de exemplo, se "não pensar em violência" ou "não cometer violência" são características associadas à normalidade e à saúde mental, pensar e agir com violência, por seu turno, está associado à anormalidadee à doença mental. 0 pensamento parece obedecer, aí, ao princípio da não contradição, um dos pilares da lógica formal. A violência e a criminalidade se apresentam, então, ligadas à anormalidade eà doença mental, de modo que a normalidade e a saúde são concebidas como não portadoras de características presentes na anormalidade e doença mental, o que reproduz a visão tradicional da saúde enquanto ausência de doença ${ }^{10}$.

No que diz respeito às ações de promoção da saúde, que mantêm o estado denormalidade esaúde mental, os presos listaram os seguintes comportamentos: estudar, trabalhar, pensar no futu- ro, pensar efazer coisas boas e certas, pensar antes de agir, ser religioso, viver do mesmo jeito, seguir as normas, praticar o bem, não usar droga, ficar calmo eem paz, não dar ouvido aos outros, cuidar desi enão se envolver com o crime. Tais resultados podem ser apreendidos através da Figura 3.

Verificamos que a ausência de envolvimento com a criminalidade, além de ser visualizada como um signo de normalidade e saúde mental, foi percebida também como uma ação de promoção da saúde mental. Da mesma forma, outros comportamentos tidos como signos de normalidade e saúdemental foram também considerados como ações de promoção da saúde mental. Isso parece corroborar mais uma vez a tese de Bibeau e Corin ${ }^{48}$, segundo a qual há um sistema de signos, significados e práticas de saúde mental. No estudo realizado no litoral norte da Bahia, os resultados também apontaram para a existência desse sistema ${ }^{7}$. A idéia de Bibeau e Corin, segundo a qual os signos de um problema mental adquirem determinados significados e conduzem a certas ações, configurando um 


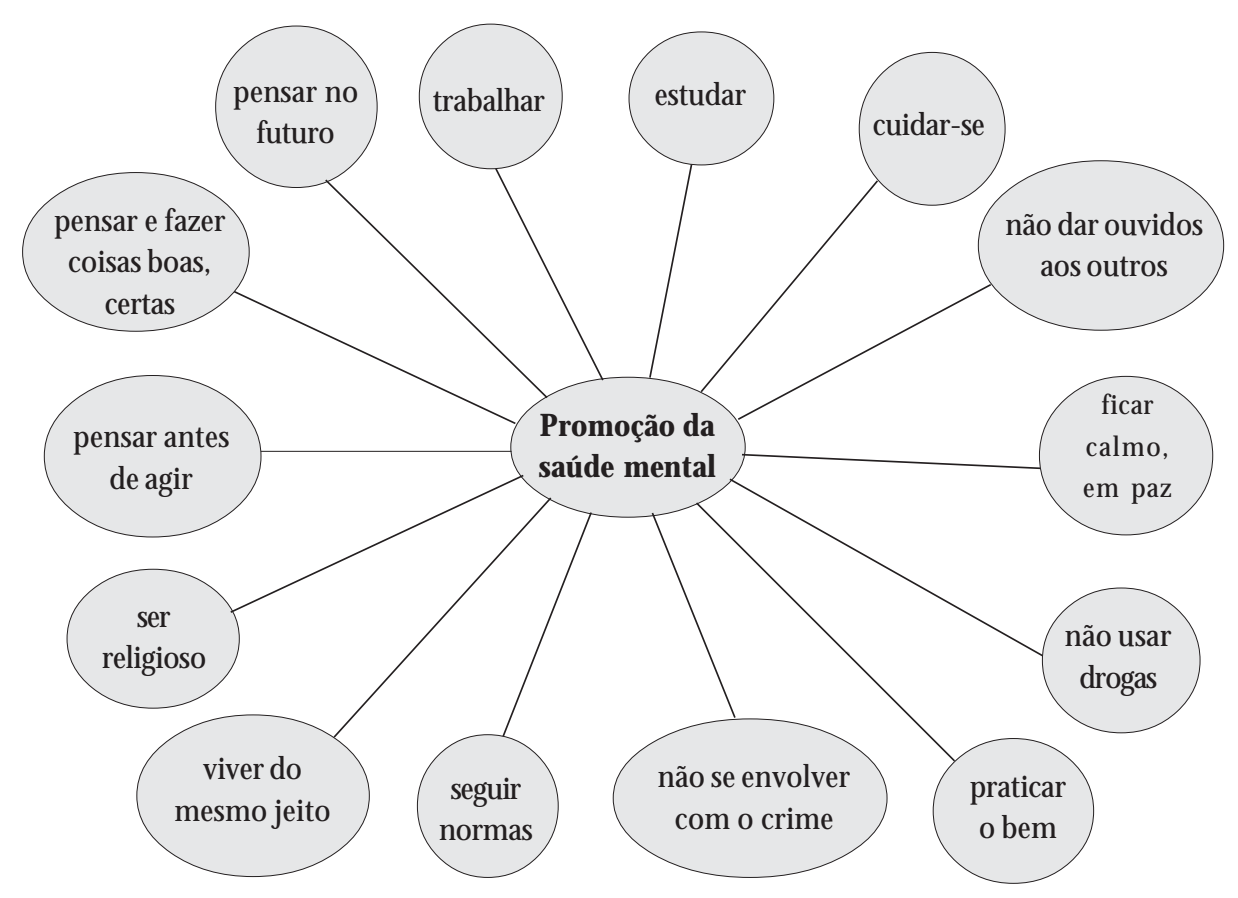

Figura 3. Ações de promoção da saúde.

sistema designos, significados e práticas, refletetambém a promoção da saúde mental.

Com relação às ações de normalização ou cura, os entrevistados relataram que os comportamentos de pensar antes de agir, estudar, buscar a ajuda dos professores, trabalhar, manter a mente ocupada com coisas boas, ficar calmo, controlar-se, buscar Jesus, não usar droga, ir ao hospital, ao centro religioso, ao médico, ao psiquiatra, ao psicólogo e não fazer maldade a ninguém podem curar ou normalizar alguém. Tais resultados podem ser visualizados na Figura 4.

É interessante observar que alguns signos de normalidademental, como estudar, trabal har enão fazer maldade a ninguém, constituem, ao mesmo tempo, ações de promoção da saúde e de cura ou normalização. Tal aspecto aponta para a co-incidência de alguns procedimentos, que podem ser terapêuticos ou promotores da saúde, a depender da situação em que se apresentem. Promover a saúde, nesses casos, é realizar atos que também são terapêuticos na presença da doença, ao mes- mo tempo em que fazer a terapêutica élançar mão de ações que também são promotoras da saúde na ausência da doença.

Quanto à auto-percepção em relação à normalidade e à saúde mental, a grande maioria dos internos $(n=24)$ revelou que se percebia como saudável e normal. Essa freqüência, entretanto, diminuiu significativamente $(n=16)$ quando el es trataram do seu estado de normalidade durante a realização do crime. Ou seja, apesar de $43 \%$ dos entrevistados $(n=12)$ não se considerarem normais durante 0 crime, $86 \%$ deles ( $n=24$ ) afirmaram que se percebiam como normais. Verificamos, assim, que, no que diz respeito a suas vidas, esses presos percebem a associação entre o crime ea anormalidademental como sendo mais denatureza situacional. Quando eles, entretanto, são inqui ridos sobre a relação entrea violência ea saúdemental, deuma forma em geral, apresentam uma associação mais estreita entrea violência, o crime, a anormalidadee a doença mental, o que parece apontar para uma perspectiva mais ideal, para um valor social. 


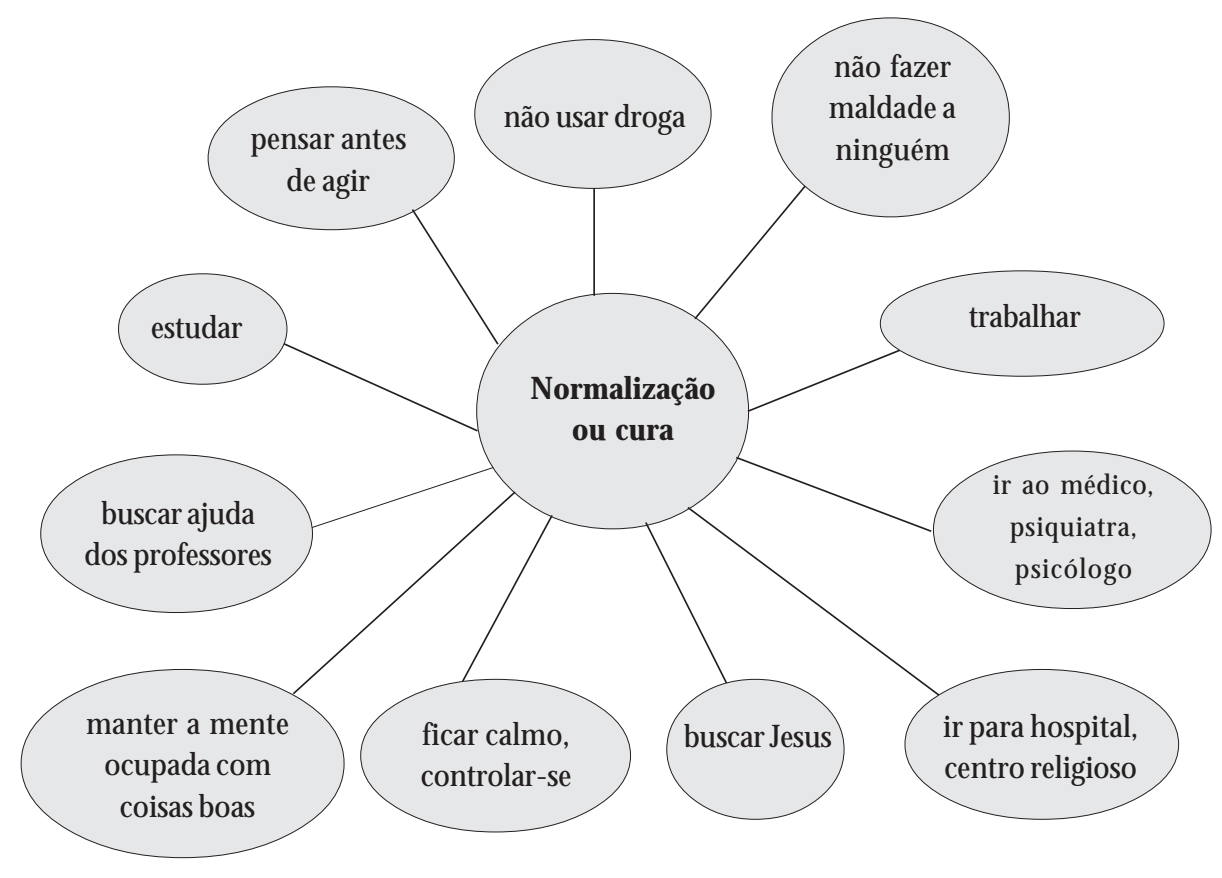

Figura 4. Ações de normalização ou cura.

Tal perspectiva pode estar ligada ao processo denormificação, descrito por Goffman ${ }^{26}$. Deacordo com esse processo, os estigmatizados podem se esforçar para se apresentarem como uma pessoa comum, já que o fato de ser normal possibilita a obtenção de gratificações. Podemos também conjecturar que o sistema prisional contribui para essas relações estabelecidas pel os presos entre a normalidade, a saúde mental, a violência e a criminalidade. A percepção da normalidade como ligada ao que é tido como comum é uma idéia que se encontra presente entre os detentos. Numa prisão, por motivos óbvios, a violência criminal é algo comum, logo ela seria considerada como al go normal. Tal associação pode constituir um dos fatores que contribuem para a auto-percepção dos entrevistados como indivíduos saudáveis e normais. A subjetividade, nessa perspectiva, nunca é absoluta e está sempre relacionada com o contexto, o quese aproxima do pensamento de Samaja ${ }^{39}$, como vimos acima. Que o desvio pode integrar a normalidade é algo que o próprio Canguilhem ${ }^{17}$ chamou a atenção, em sua brilhante tese "O normal e o patológico", na década de 1940.

\section{Consideraçõesfinais}

Os estudos efetuados com as parcelas da população envolvidas com a violência criminal tanto podem ser úteis para a elaboração de políticas e práticas ligadas à saúde pública, quanto podem colaborar para a construção de uma teoria geral sobre a saúde. Vimos que as diferentes concepções sobre a normalidade e a saúde mental apontam para a complexidade do objeto "saúde", cuja estrutura é atravessada por distintos aspectos e processos biopsicossociais, em interação complexa uns com os outros. De acordo com esta pesquisa, verificamos que as concepções de normalidade e saúde dos presos reproduzem, em muitos aspectos, aquelas apresentadas pelos outros segmentos da população, que não cometeram um delito. Entretanto, as concepções dos detentos fazem uma referência ex- 
plícita ao comportamento criminoso, seja ressaltando uma relação de exclusão entre a normalidade e a saúde mental com a violência e a criminalidade, seja defendendo a coexistência destes termos. N uma perspectiva geral, a anormalidadee a doença mental estão associadas, como vimos, à violência e à criminalidade. Entretanto, os presos entrevistados não se consideraram nem anormais nem violentos por terem cometido um delito. Esse aspecto parece apontar para a existência de duas diferentes visões: uma que reproduz a relação de exclusão entre a normalidade, a saúde e a violência criminal, e outra que admite a co-incidência entre tais termos. 0 tipo de delito praticado pela maioria dos entrevistados (roubo) pode ter sido um dos fatores que contribuiu para tal concepção. 0 fato desses detentos não estarem sob tratamento no manicômio judiciário reforça a idéia de que eles não possuem uma anormalidade ou doença mental, o quenão exclui a possi bilidade deles portarem algum transtorno psíquico e necessitarem de assistência psicológica e/ou psiquiátrica. A própria perda da liberdadee a concomitante reclusão numa unidade prisional já, por si só, são fatores que podem colaborar para a eclosão ou agravamento de um transtorno.

\section{Referências}

1. Corin E, U chôa E, Bibeau G, Harnois G. Les attitudes dans le champ de la santé mentale: repères théoriques et méthodologiques pour une étude ethnographique et comparative. Rapport Technique. Montréal: Centre de Recherche de I'H ôpital Douglas, Centre Collaborateur OM S; 1989. [M imeo]

2. Bibeau G. Hay una enfermidad en las Americas? Outro caminho de la antropologia médica para nuestro tiempo. In: Pinzón C, Suárez PR, Garay G, editores. Cultura y salud en la construcción de las Américas. Bogotá: Instituto Colombiano de Antropología; 1993. p. 41-70.

3. Almeida Filho N, Coelho M TAD, Peres MFT. O conceito de saúde mental. Revista USP 1999; 43:100-125.

4. Coelho MTAD, Almeida Filho N. Normal-patológico, saúde-doença: revisitando Canguilhem. Physis 2000; 9:13-36.

5. Coelho MTAD, Almeida Filho N. Conceitos de saúde em discursos contemporâneos de referência científica. Hist. cienc. saude - $M$ anguinhos 2002; 9(2):315-333.

6. Coelho MTAD, Almeida Filho N. Análise do conceito de saúde a partir da epistemologia de Canguilhem e Foucault. In: Goldenberg P, M arsiglia RM G, Gomes MHA, organizadores. 0 clássico e o novo: tendências, objetos e abordagens em ciências sociais e saúde. Rio de Janeiro: Fiocruz; 2003. p. 101-113.
7. Coelho MTAD, Almeida Filho N. Concepções populares de normalidade e saúde mental no litoral norte da Bahia, Brasil. Cad. Saúde Pública 2005; 21(6):17261736.

8. Almeida Filho N. O conceito de saúde: ponto cego da epidemiologia? Rev. bras. epidemiol. 2000; 3(1-3):4-20.

9. Almeida Filho N. For a General Theory of Health: preliminary epistemological and anthropological notes. Cad Saúde Pública 2001; 17(4):753-770.

10. Almeida Filho N, Jucá V. Saúde como ausência de doença: crítica à teoria funcionalista de Christopher Boorse. Cien. Saude Colet 2002; 7(4):879-889.

11. Berger $\mathrm{H}$. Health promotion - a new approach in psychiatry. Psychiatr Prax 2003; 30(1):14-20.

12. Maoz B, Rabin S. Salutogenesis - a story about the development of an idea. Harefuah 2003; 142(7):550553.

13. Salerno S, Marchetti E, Figà-Talamanca I. The concept of health in Italian occupational health legislation. Epidemiol Prev 2003; 27(4):244-246.

14. Waters E, Stewart-Brown S, Fitzpatrick R. Agreement between adolescent self-report and parent reports of health and well-being: results of an epidemiological study. Child Care Health Dev 2003; 29(6):501-509.

15. Wang W. Mainland Chinese students' concept of health. Asia Pac J Public Health 2004; 16(2):89-94. 
16. Medeiros PF, Bernardes AG, Guareschi NMF. O conceito de saúde e suas implicações nas práticas psicológicas. Psic.: Teor. e Pesq. 2005; 21(3): 263-269.

17. Canguilhem G. 0 normal e o patológico. Rio de Janeiro: Forense Universitária; 1978.

18. Freud S. A psicopatologia da vida cotidiana. In: Freud S. Edição standard brasileira das obras psicológicas completas de Sigmund Freud. Rio de Janeiro: Imago Editora; 1980.

19. Freud S. Leonardo da Vinci e uma lembrança da sua infância. In: Freud S. Edição standard brasileira das obras psicológicas completas de Sigmund Freud. Rio de Janeiro: I mago Editora; 1980.

20. Freud S. Conferências introdutórias sobre psicanálise. In: Freud S. Edição standard brasileira das obras psicológicas completas de Sigmund Freud. Rio de Janeiro: Imago Editora; 1980.

21. Freud S. A questão da análise leiga. In: Freud S. Edição standard brasileira das obras psicológicas completas de Sigmund Freud. Rio de Janeiro: Imago Editora; 1980.

22. Freud S. Análise terminável e interminável. In: Freud S. Edição standard brasileira das obras psicológicas completas de Sigmund Freud. Rio de Janeiro: I mago Editora; 1980.

23. Freud S. Moisés e o monoteísmo. In: Freud S. Edição standard brasileira das obras psicológicas completas de Sigmund Freud. Rio de Janeiro: Imago Editora; 1980.

24. Freud S. A perda da realidade na neurose e na psicose. Edição standard brasileira das obras psicológicas completas de Sigmund Freud. In: Freud S. Rio de Janeiro: Imago Editora; 1980.

25. Jaspers K. Psicopatologia geral: psicologia compreensiva, explicativa e fenomenologia. Rio de Janeiro: Atheneu; 1985.

26. Goffman E. Estigma: notas sobre a manipulação da identidade deteriorada. Rio de Janeiro: Zahar Editores; 1975.

27. Becker HS. Outsiders: studies in the sociology of deviance. New York: Free Press; 1963.

28. Scheff TJ. Being mentally ill: a sociological theory. Chicago: Aldine; 1966.

29. Kleinman A. Patients and healers in the context of culture. Berkeley: University of California Press; 1980.

30. Kleinman A. Concepts and a model for the comparison of medical systems as cultural systems. Social Science and M edicine 1978; 12B:85-94.

31. Kleinman A. The illness narratives: suffering, healing $\&$ the human condition. N ew York: Basic Books; 1988.

32. Good BJ. Medicine, racionality, and experience. An anthropological perspective. New York: Cambridge University Press; 1994.

33. Good BJ, M ary-Jo Good. The meaning of symptoms: a cultural hermeneutic model for clinical practice. In: Eisenberg L, Kleinman A, editors. The relevance of social science for medicine. Dordrechet: Reidel Publishing Co; 1980. p. 165-196.

34. Young $A$. The anthropologies of illness and sickness. Ann. Rev. Anthropol. 1982; 11:257-285.

35. Bibeau G. A step toward thick thinking: from webs of significance to connections across dimensions. M edical Anthropology Quarterly 1988; 2:402-416.
36. Corin E. The cultural frame: context and meaning in the construction of health. In: Benjamin C, Amick III, Sol Levine, Alvin R Tarlov, Diana Chapman Walsh, editors. Society and health. New York: Oxford University Press; 1995. p. 272-304.

37. Devereux G. Normal and abnormal: the key problem of psychiatric anthropology. In: Bennt JW, Devereux G, Paul BD, Gladwin T, editors. Some uses of anthropology: theoretical and applied. Washington, D.C.: The Anthropological Society of Washington; 1971. p. 2349.

38. Laplantine F. Aprender etnopsiquiatria. São Paulo: Brasiliense; 1994.

39. Samaja J. Fundamentos epistemológicos de las ciencias de la salud [tese]. Rio de Janeiro (RJ): Escola Nacional de Saúde Pública, Fiocruz; 1997.

40. Souza M FM, Kalichman AO. Vigilância à saúde: epidemiologia, serviços e qualidade de vida. In: Rouquayrol MZ, Almeida Filho N, organizadores. Epidemiologia \& Saúde. Rio de Janeiro: MEDSI; 1994. p. 467-476.

41. U chôa E, Vidal JM. Antropologia médica: elementos conceituais e metodológicos para uma abordagem da saúde e da doença. Cad Saúde Pública 1994; 10(4):497504.

42. Caponi S. Georges Canguilhem y el estatuto epistemológico del concepto de salud. Hist. cienc. saude M anguinhos 1997; 4(2):287-307.

43. Segre M, Ferraz FC. O conceito de saúde. Rev. Saúde Pública 1997; 31(5):538-542.

44. Paim JS, Almeida Filho N. A crise da saúde pública e a saúde coletiva: uma nova saúde pública ou campo aberto a novos paradigmas? Rev. Saúde Pública 1998; 32(4):299-316.

45. M artins A. N ovos paradigmas e saúde. Physis 2000; 9(1):83-112.

46. Bibeau G, Corin E. From submission to the text to interpretative violence. In: Bibeau G, Corin E, editors. Beyond textuality. Ascetism and violence in anthropological interpretation. Approaches to semiotics series. Berlin: Mouton de Gruyter; 1995. p. 3-54.

47. Almeida Filho N, Cardoso C, Alves PC, Rabelo M, Rodrigues N, Bibeau G, Corin E. Signs, meanings and practice in mental health: part II, methodological application, the Bahia study. Montréal: Department d'Anthropologie,U niversité de Montréal; 1998.

48. Bibeau G, Corin E. Culturaliser I'épidémiologie psychiatrique. Les systèmes de signes, de sens et d'action en santé mentale. In: Charest $P$, Trudel $F$, Breton Y, editors. Marc-Adélard Tremblay ou la construction de l'anthropologie québécoise. Quebec: Presses de I'U niversité Laval; 1994. p. 105-148.

Artigo apresentado em 30/04/2007

Aprovado em 20/12/2007 